\title{
Technology in Indian agriculture - a review
}

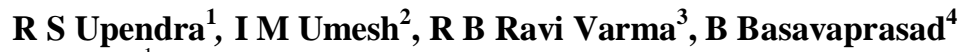 \\ ${ }^{1}$ Department of Biotechnology, Reva University, India \\ ${ }^{2,3}$ Department of Information Science Engineering, RV College of Engineering, India \\ ${ }^{4}$ Department of Computer Science, Govt First Grade College, India
}

\begin{tabular}{l}
\hline Article Info \\
\hline Article history: \\
Received Feb 5, 2020 \\
Revised May 7, 2020 \\
Accepted May 21, 2020 \\
\hline
\end{tabular}

\section{Keywords:}

Agriculture

Big data analytics

Crop management

Crop yield

Digital agriculture

Precision agriculture

Smart forming

\begin{abstract}
Optimization of agricultural practices for enhanced crop yield is considered to be essential phenomena for the countries like India. In order to strengthen the economy and also to meet the food demand for the exponentially growing population, optimizing the agricultural practices has become necessity. In India, weather and geographical conditions are highly variable and were thought to be the major bottleneck of agricultural practices to achieve improved crop yield. Agricultural practices in India are facing many challenges such as change in climatic conditions, different geographical environment, conventional agricultural practices; economic and political scenario. Economic loss due to the lack of information on crop yield productivity is another major concern in the country. These hurdles can be overcome by the implementation of advanced technology in agriculture. Some of the trends observed are smart farming, digital agriculture and Big Data Analytics which provide useful information regarding various crop yields influencing factors and predicting the accurate amounts of crop yield. The exact prediction of crop yield helps formers to develop a suitable cultivation plan, crop health monitoring system, management of crop yield efficiently and also to establish the business strategy in order to decrease economic losses. This also makes the agricultural practices as one of the highly profitable ventures. This paper presents insights on the various applications of technology advancements in agriculture such as Digital Agriculture, Smart Farming or Internet of Agriculture Technology (IoAT), Crop Management, Weed and Pest control, Crop protection and Big data analytics.
\end{abstract}

Copyright () 2020 Institute of Advanced Engineering and Science. All rights reserved.

\section{Corresponding Author:}

R S Upendra,

Department of Biotechnology,

Reva University, Bengaluru, Karnataka, India.

Email: upendrars@reva.edu.in

\section{INTRODUCTION}

Agriculture is the basis for food security and survival. Mankind living on the globe depends majorly on the agri based crops for their survival. India is an agricultural dependent country and the fact that the majority of the populations are vegetarians and solely depends on the agricultural products for their survival. Being an agricultural based nation, country's economy is principally influenced by annual crop yields of agricultural practices. Recent survey indicates that more than $60 \%$ of the population is in to agriculture and the majority among the rest is connected to the other aspects of agricultural practices. The other facets of agricultural practices include agricultural machinery companies, fertilizer companies, crop yield marketing and sales companies etc. Agriculture activities help humans to raise the most principle food crops with ideal animal population to achieve environmental balance. In the country like India, farmers cultivate major food crops such as rice, wheat, cereals, pulses, different vegetables known as onions, potatoes, sugarcane, oil seeds, mango, orange, red chilli and also various commercial crops such as coconut, coffee, tea, cotton, rubber and jute. The majority of the rural population close to $70 \%$ depends on 
the agriculture for their household. Agriculture contributes approximately 18\% to the total GDP of the country and provides employment to over 60 to $70 \%$ of the population in India [1, 2].

At present India stands second globally in terms of agricultural based products. Cultivation of various agricultural crops influences the economy of the country at broadest range and plays a pivotal role in the overall in socio-economic structure of the country. The success rates of agri practices majorly influenced by certain factors namely soil fertility, climatic conditions, weather forecast, temperature, water level with the rainfall measures, irrigation condition, fertilizers availability, pesticide used, controlling of weed population, process of cultivation, harvesting methods employed and economic and political scenarios [3]. Majority of the former communities in India predict crop yield based on the conventional practice with the knowledge of previous experiences, but this approaches alone may not be efficient as the climatic conditions keep changing drastically due to the overall change in the weather forecast at global level. In order to address this issue, a more scientific methodology with technology advent known as agro based big data analytics is essential. Big data analytics provides an opportunity to analyze the significant factors that controls the crop yield and also about the socio, economic and political impacts on the success rates of the various agricultural practices [4]. Higher crop yield can be achieved by increasing the overall cultivable land suitable for the growth of particular crop and also by decreasing the crop damage, overall operating cost through implementation of good agricultural practices. The enhanced crop yield can be reported by controlling the major factors of the agricultural practice such as fertilizer type and quantity, water resources and levels, quality of the seed used for cropping, minimization of biotic stress caused by weeds, pests and the control of abiotic stress [5]. Manual and conventional methods such as physical crop inspection and manual removal of weeds and contaminants are not very effective approaches and do possess significant limitations in supporting the higher crop yield [6]. On the other hand, the sensor mounted practices can be effective in understanding the needs of the agricultural conditions of the growing crop in a much scientific way $[4,7]$. The Big data analytics is one such technology, which provides an opportunity to analyse the various crop yield influencing factors to provide an optimum condition for the enhanced crop yields and also helps in designing the strategies for crop yield marketing $[8,9]$.

\section{TECHNOLOGY IN AGRICULTURE}

\subsection{Digital agriculture}

Digital agriculture is the use of new and advanced technologies, integrated into one system, to enable farmers and other stakeholders within the agriculture value chain to improve food production. In comparison with conventional and sensor based approaches, an advanced approach termed as digital agriculture can help the farmers to understand their agricultural practices in a much better and effective way in a real time manner. Thus, digital agriculture holds profound impact on the crop yield enhancements, by empowering the formers with required scientific knowledge to implement good agricultural practices as shown in Figure 1.

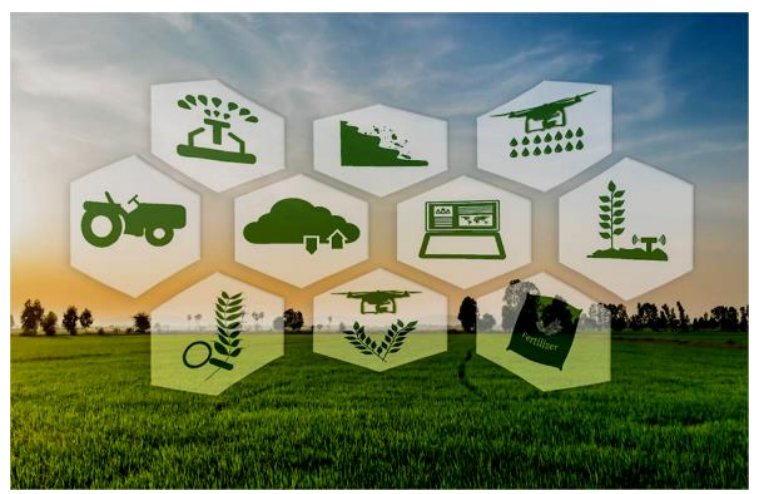

Figure 1. The concept of digital agriculture [10]

The user interface system used in digital agriculture provides opportunity to the formers to share their ideas. This also helps them to get knowledge about different kind of cultivation procedures implemented in the different parts of the globe for the particular crop and equip them with technological advances and business skills to make their agricultural practices as successful venture. Digital agriculture helps formers in maintaining their inherent agricultural practices and at the same time provides useful information to update 
their knowledge and the skills. It also provides an opportunity to review the historical information in understanding the various situations and difficulties to gain an essential knowledge in taking the right decisions. The composite agricultural practices combined with rigorous and enhanced crop yield require an implementation of robust automated systems with less development time at low cost. Agricultural safety is a big concern in current scenario which can be implemented by controlling the various contaminants that promote crop damage. Agricultural automation systems including field machinery, irrigation systems, greenhouse automation, animal automation systems, and automation of fruit production systems helps in achieving enhanced crop yields [11, 12].

\subsection{Smart farming}

Smart Farming is a development that emphasizes the use of information and communication technology in the cyber-physical farm management cycle [13]. Smart Farming represents the application of modern Information and Communication Technologies (ICT) into agriculture, leading to what can be called a Third Green Revolution. Agricultural based practices in India needs indefinite transition from the conventional methods to the smart farming approaches in order to achieve sustainable and profitable agricultural practices. Smart forming also termed as Internet of Agriculture Technology (IoAT), employs Information and Communication Technologies (ICT) in understanding the various aspects of the farming practices and help the farmers to maintain the optimum conditions with least effort and higher cost benefits to achieve more proficient, highly productive, cost effective and profitable farming enterprises. Smart farming models are found to be more generic, easy to understand and easy to adapt by the farmers as shown in Figure 2.

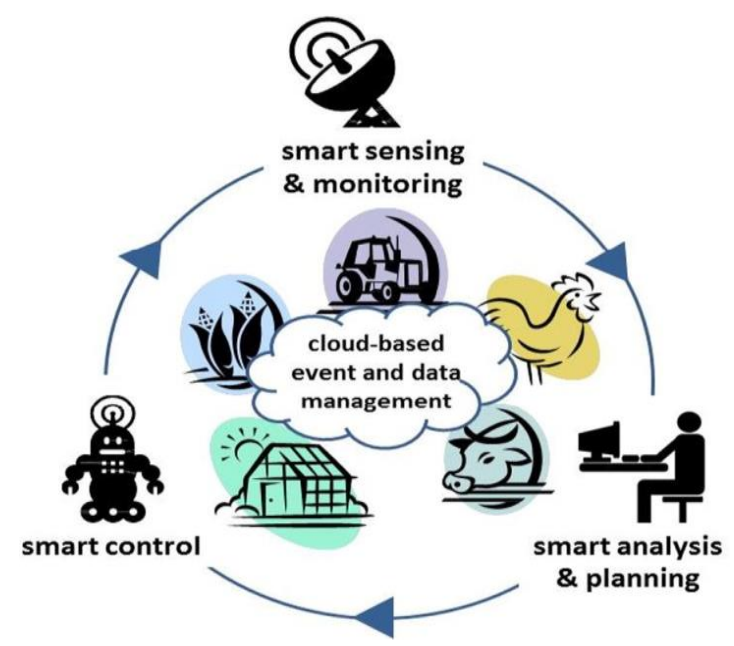

Figure 2. The concept of smart farming representing the cyber-physical system based management cycle [14]

As per the recent survey, the world population is going to reach close to 10 billion by the year 2050 . Providing the food for these mammoth populations is considered to be a big challenge for the governments, and it is highly impossible with less cultivable land available and conventional agricultural approaches. The only way to deal this ample task is the implantation of smart agricultural practices and the application of IoT technology in agriculture to overcome the crop limiting hurdles such as biotic and abiotic stress, crop failure, crop damage, loss of productitivity and wastage to achieve progression in the agricultural practices. IoAT refer to the application of various sensors to monitor the different conditions such as light intensity, humidity percent, temperature measures, soil moisture content etc. in real-time situation and also helps in the automation of irrigation system to reduce water wastage. The benefits provided by the IoAT is ample and some of the most important benefits are listed to be sensor based field monitoring, effective resource mapping, remote crop monitoring, climate monitoring \& forecasting, controlled usage of fertilizers and pesticides and finally the accurate prediction of crop yield $[15,16]$.

\subsection{Supply chain strategies}

Food security is one of the most important, critical and major concerns globally today and world is going to face an immense food crisis in coming years. To accommodate future needs of the growing population with the limited availability of cultivable land, it is imperative to decrease product and food losses 
by strengthening the food security measures through automated food security supply chain approaches as shown in Figure 3. Automation is very much essential in all the stages of cultivation i.e., selection of quality seed, process of planting seeds, growing the young plantlets, establishing protection from pets to avoid crop damage, supplying the nutrients and water at optimal level to decrease crop failure and increase crop productivity. Other applications of automation include controlled and effective harvesting method to decrease crop wastage, post harvest collection of crop, processing of collected crop and transportation for marketing. Food safety measure brings confidence and increase acceptability of the consumers on products or food items. This can be achieved by denoting the safety measures implemented in all the stages i.e process of cultivation, harvest and post harvest operations, of crop management. Safety measures implanted through automated food chain approaches give more business to the industry and also furnish reputation to the formers which increase their confidence and attract more people towards agricultural practices.
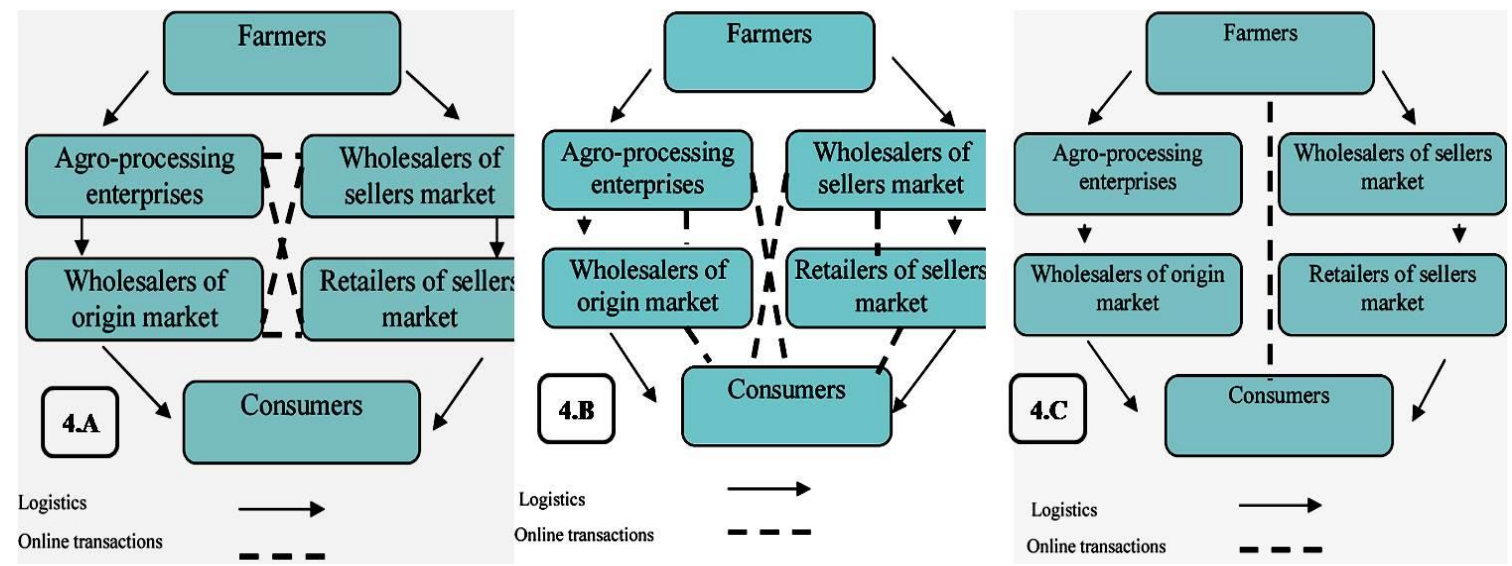

Figure 3. Models practiced in supply chain strategies of agriculture practices, (a) B2B model, (b) B2C model, (c) C2C model [17]

Application of big data analytics certainly helps in overcoming the hurdles in food supply chain by integrating with Application Programming Interface (API) system. Big data analytics can certainly add value to the agricultural practice in many regards such as bringing the returns from scientific investments, establishing the good agricultural practice, implementation of precision agricultural based techniques at field level, efficient food supply chain mechanism and automation of the total process for the profitable agriculture $[18,19]$.

\subsection{Data mining and analytics}

Decision support system (DSS) in the field of agriculture is ably supported by data mining tools. The main aim of the processes involved in data mining is to extract the information from the currently available data sets and then transform the same using specific tools to a unique format that is easily understandable and can be used for advanced purposes as shown in Figure 4. Data mining helps in soil fertility studies and empowers the farmers in making a decision to sow specific variety of the crop that results in a better yield. The main aim of soil classification is to predict the engineering properties and fertilizer of soil there by order the choices for use. The currently available statistical techniques and the laboratory test consume lot of time, energy and money. It is possible to develop more efficient techniques for solving complex and large data sets of soil with improved accuracy and effectiveness. Data mining techniques based on GPS, k-means approach, SVMs, K-nearest fertilize method are useful to study the soil characteristics, pollution in atmosphere, the factors that influence the crop yield.

Soil tests are normally conducted to study the fertility of the soil, impurity and other deficiencies if any in soil that to be removed. Most of the Soil testing laboratories that are owned by either government or private sector offer different protocols for analysis of the soil and the literature pertaining to the soil characteristics. Suitable fertilizers are recommended based on the data available with reference to the soil composition. This helps the formers to apply a suitable fertilizer for specific crops during that season [20-21]. 


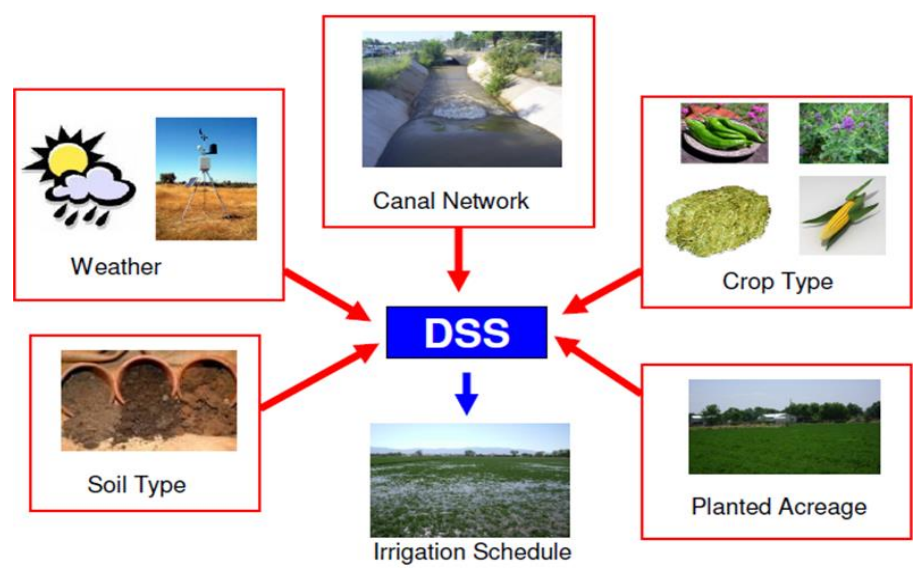

Figure 4. An architecture of decision support system (DSS) applied in the field of agriculture [22]

\subsection{Weather forecasting techniques}

One of the greatest challenges for agriculture is climate change and its impact on human life. In contrary to other fields like e-commerce and advertising where Big Data has played big role in their success, there is little impact on advanced understanding of the environment. This inconsistency curtails the climate data with complex nature. Big data analytics has been in use to mine large datasets of climate with more focus of differences between the traditional big data and mining climate data approaches [23]. In India the impact of climate change effects plant growth development and subsequently crop yield. Due to the increase in the temperatures, there is a drastic reduction in the duration of the crop. Increase in crop respiration rate had resulted in pattern change of pest attack. Most of the crops have adjusted to the growing season, day lengths of the middle and lower latitudes and with poor response to the much longer days of the summer. Increased temperature accelerates the rate of release of $\mathrm{CO}_{2}$ during warmer seasons resulting in reduced crop yield. By collecting the data of rainfall and temperature of last 5 years one can analyze the data by using different big data analytics tools to get the exact change in the Indian agricultural climate [24]. Sensors play a vital role in predicting the effectiveness of the certain seeds, fertilizer in different section of the farm as shown in Figure 5. To achieve an optimum crop yield, software guides the farmers to sow the hybrid varieties seeds at one corner and different variety at another corner [25].

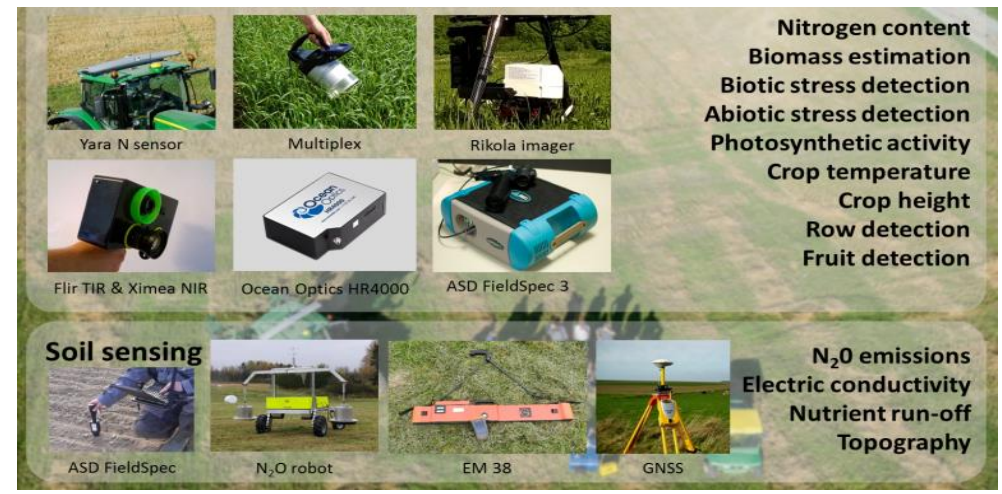

Figure 5. Sensors applied in the field of agriculture [26]

\subsection{Agriculture/ crop management}

Various seasonal, economic and biological factors influence the crop production but unpredictable changes in these factors lead to a great loss to farmers [27]. Crop protection \& weed control solutions need to be developed to reduce the crop damage and in turn increase the overall yield of the crop. The existing models consist of three major elements: (i) Data Capture \& Storing. (ii) Data Analysis and (iii) Recommendations based on analytics. This unified solution need concurrent advances in the domains of agricultural science, collaboration between supply chain partners and in ICT. New techniques are required to 
use the historical data for prediction of the occurrence of pests, weeds and other diseases [28, 29]. Integrated Crop Management System (ICMs) is a technique of agricultural practices that balances the necessities of organizing a profitable agri based business with environmental accountability as shown in Figure 6. ICMs includes practices that helps to reduce waste, boost energy efficiency and diminish pollution. Technology used for agriculture has positive impact [30-39].

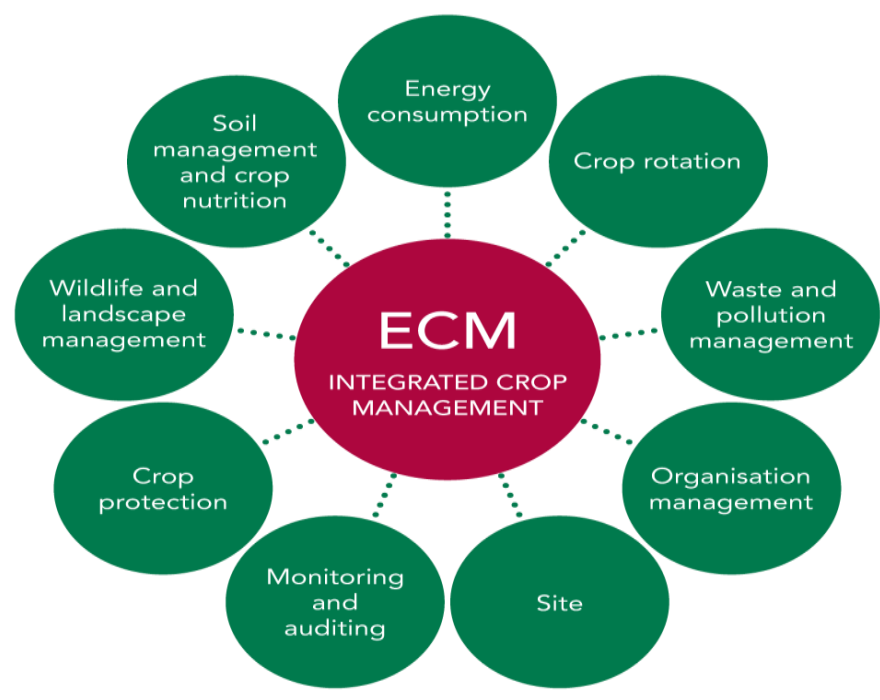

Figure 6. Application of integrated crop management (ICMs) in agriculture [40]

\section{CONCLUSION}

From the survey of technology usage in agriculture, it can be observed that there are numerous approaches that can be used for improving the quality and quantity of crops. In contrast to other developed countries, in India it is a big challenge to achieve the anticipated growth due to non-maintenance of resources on which the production systems depend. Various elements influence the successful use of quality farming.

The usage of technology in agriculture domain has resulted in digital agriculture, precision agriculture, analytics for crop yield etc. In India, large numbers of people are engaged in agriculture and there is a gap between the farmers and technology. Governments have introduced various methods into agriculture to help the farmers to take the advantage of technology. In spite of this, there is a scope for user friendly easily understandable agro advisory systems to help farmers to take decision on crops to be sown. Also at different levels of crops growth, these technological inventions should help farmers to extract best yield with reduced expenses. There exists a scope for research in this area.

\section{REFERENCES}

[1] K. M. Arjun, "Indian Agriculture- Status, Importance and Role in Indian Economy," International Journal of Agriculture and Food Science Technology, vol. 4, no. 4, pp. 343-346, 2013.

[2] https://en.wikipedia.org/wiki/Economy_of_India\#cite_note-WTTCBenchmark-146.

[3] J. Majumdar, et al., "Analysis of agriculture data using datamining techniques: application of big data," Journal of Bigdata, vol. 4, pp. 1-15, 2017.

[4] J. W. Jones, et al., "Toward a new generation of agricultural system data, models, and knowledge products: State of agricultural systems science," Agricultural Systems, pp. 269-288, 2017.

[5] L. Mariani and A. Ferrante, "Agronomic Management for Enhancing Plant Tolerance to Abiotic StressesDrought, Salinity, Hypoxia, and Lodging," Horticulturae, vol. 3, no. 4, pp. 52-69, 2017.

[6] H. F. Abouziena and W. M. Haggag, "Weed control in clean agriculture: A review," Planta daninha, vol. 34, no. 2, pp. 377-392, 2016.

[7] D. Ramesh and B. V. Vardhan, "Data Mining Techniques and Applications to Agricultural Yield Data," International Journal of Advanced Research in Computer and Communication Engineering, vol. 2, no. 9, pp. 3477-3480, 2013.

[8] D. Jiménez, et al., "From Observation to Information: Data-Driven Understanding of on Farm Yield Variation," PloS ONE, vol. 11, no. 3, pp. 1-20, 2016. 
[9] B. M. Sagar and Cauvery N. K., "Agriculture Data Analytics in Crop Yield Estimation: A Critical Review," Indonesian Journal of Electrical Engineering and Computer Science, vol. 12, no. 3, pp. 1087-1093, 2018.

[10] http://breakthrough.unglobalcompact.org/disruptive-technologies/digital-agriculture/.

[11] Y. Edan, et al., “Automation in Agriculture,” Springer Handbook of Automation, pp. 1095- 1128, 2009.

[12] R. R. Shamshiri, et al., "Advances in greenhouse automation and controlled environment agriculture: A transition to plant factories and urban agriculture," International Journal of Agricultural \& Biological Engineering, vol. 11, no. 1, pp. 1-22, 2018.

[13] T. G. Babu and G. A. Babu, "Data Analytics to Produce Big Results in the Agricultural Sector," International Journal of Advanced Research in Biology Engineering Science and Technology, vol. 2, no. 3, pp. 67-75, 2016.

[14] S. Wolfert, et al., "A Future Internet Collaboration Platform for Safe and Healthy Food from Farm to Fork," Annual SRII. Global Conference, San Jose, CA, USA, pp. 266-273, 2014.

[15] P. P. Jayaraman, et al., "Internet of Things Platform for Smart Farming: Experiences and Lessons Learnt," Sensors, vol. 16, pp. 1-17, 2016.

[16] M. J. O'Grady and G. M. P. O'Hare, "Modelling the smart farm," Information Processing in Agriculture, vol. 4, no. 3, pp. 179-187, 2017.

[17] G. Lin and H. Zhongwei, "Analysis of agricultural products e-commerce models based on supply chain management," International Conference on E-Business and E-Government (ICEE), pp. 1-3, 2011.

[18] D. Tsiolias, et al., "Big Data and Agricultural Supply Chains: Opportunities for Increased Food Security," Proceedings of the Homburg International conference of Logistics (HICL), vol. 22, pp. 331-354, 2015.

[19] C. C. Sekhar, et al., "Effective use of Big Data Analytics in Crop planning to increase Agriculture Production in India," International Journal of Advanced Science and Technology, vol. 113, pp. 31-40, 2018.

[20] N. Mirjankar and S. Hiremath, "Application of Data Mining in Agriculture Field," International Journal of Computer Engineering and Applications (iCCSTAR-2016), pp. 363-368, 2016.

[21] C. C. Baseca, et al., "A Smart Decision System for Digital Farming,” Agronomy, vol. 9, no. 5, pp. 216-234, 2019.

[22] K. D. Kinzli, et al., "Linking a developed decision support system with advanced methodologies for optimized agricultural water delivery, Efficient Decision Support Systems-Practice and Challenges in Multidisciplinary Domains," IntechOpen, pp. 187-212, 2011.

[23] A. S. Rani, "The Impact of Data Analytics in Crop Management based on Weather Conditions," International Journal of Engineering Technology Science and Research, vol. 4, no. 5, pp. 299-308, 2017.

[24] A. Tripathi and A. K. Mishra, "Knowledge and passive adaptation to climate change: An example from Indian farmers," Climate Risk Management, vol. 16, pp. 195-207, 2017.

[25] S. Pongnumkul, et al., "Applications of Smartphone-Based Sensors in Agriculture: A Systematic Review of Research," Journal of Sensors, vol. 2015, pp. 1-18, 2015.

[26] K. Kusnierek and A. Korsaeth, "Simultaneous identification of spring wheat nitrogen and water status using visible and near infrared spectra and powered partial least squares regression," Computers and Electronics in Agriculture, vol. 117, pp. 200-213, 2015.

[27] Dhivya B. H., et al., "A Survey on Crop Yield Prediction based on Agricultural Data," International Journal of Innovative Research in Science, Engineering and Technology, vol. 6, no. 3, pp. 4177-4182, 2017.

[28] F. K. Van Evert, et al., "Big Data for weed control and crop protection," John Wiley \& Sons Ltd on behalf of European Weed Research Society, pp. 218-233, 2017.

[29] M. Donatelli, et al., "Modelling the impacts of pests and diseases on agricultural systems," Agricultural Systems, vol. 155, pp. 213-224, 2017.

[30] S. Brdar, et al., "Support vector machines with features contribution analysis for agricultural yield prediction," Proceedings of the Second International Workshop on Sensing Technologies in Agriculture, Forestry and Environment (EcoSense), Belgrade, pp. 43-47, 2011.

[31] F. Chang, et al., "Bigtable: a distributed storage system for structured data," 7th USENIX Symposium on Operating Systems Design and Implementation (OSDI), pp. 205-218, 2006.

[32] S. Christensen, et al., "Site-specific weed control technologies," Weed Research, vol. 49, pp. 233-241, 2009.

[33] E. F. Codd, "A relational model of data for large shared data banks," Communications of the ACM, vol. 13, no. 6 , pp. $377-387,1970$.

[34] H. Kashyap, et al., "Big data Analytics in Bioinformatics: A Machine Learning Perspective," Journal of Latex Class Files, vol. 13, no. 9, pp. 1-20, 2014.

[35] C. Kempenaar, et al., "Towards data-intensive, more sustainable farming: advances in predicting crop growth and use of variable rate technology in arable crops in the Netherlands," 13th International Conference on Precision Agriculture (ICPA), St. Louis, MO, USA, 2016.

[36] E. Nozari, et al., "Differentially private distributed convex optimization via objective Perturbation," American Control Conference (ACC), Boston, MA, USA, pp. 2061-2066, 2016.

[37] J. Peknic'ova and K. B. Bimova, "Application of species distribution models for protected areas threatened by invasive plants," Journal for Nature Conservation, vol. 34, pp. 1-7, 2016.

[38] O. Elijah, et al., "Production of strawberry using internet of things: a review," Indonesian Journal of Electrical Engineering and Computer Science, vol. 15, no. 3, pp. 1621-1628, 2019.

[39] S. S. Sarnin, "Smart insects repeller," Indonesian Journal of Electrical Engineering and Computer Science, vol. 17, no. 1, pp. 205-212, 2020.

[40] https://ecmltd.co.uk/integrated-crop-management/. 


\section{BIOGRAPHIES OF AUTHORS}
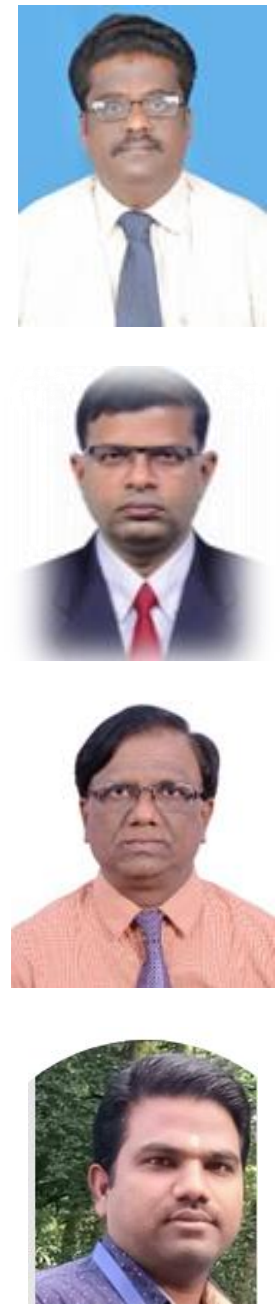

Dr. R S Upendra is presently working as an Associate Professor, Department of Biotechnology, School of Applied Sciences, Reva University, Bengaluru. He completed M.Sc, M.Tech in Biotechnology and awarded Ph.D in Applied Science (Biotechnology). He is a Life time member in ISTE. His areas of research include ANN \& GA based biosimulation modelling, Microbial and Nanobiotechnology.

Dr. I M Umesh is presently working as a System Analyst in the department of Information Science and Engineering at R V College of Engineering, Bengaluru. He completed his PhD in Computer Science in the year 2019. His research areas include Software aging and rejuvenation, Big Data Analytics and Recommendation Systems.

R B Ravi Varma is presently working as a System Administrator at RV College of Engineering, Bengaluru. He has completed his Master degree from S.V. University, Tirupati, M.S Degree in Information Technology from Mangalore University and Post Graduate Diploma in Systems Management from NIIT, Chennai. His Research interests include Big Data Analytics, Cloud Computing and Machine Learning.

Dr. Basavaprasad B is presently working as an Assistant Professor in the department of Computer Science, Govt First grade College, Raichur. He has completed his $\mathrm{PhD}$ in Computer Science in the year 2019. His research areas include Software Defined Network, Cloud Computing and IoT. 